\title{
Synthesis of Carbon Encapsulated Iron Nanoparticles from Olive Mill Wastewater for Water Remediation
}

\author{
B. Calderon*, F. Smith, I. Aracil, A. Fullana \\ University of Alicante, Department of Chemical Engineering, Alicante, Spain \\ San Vicente del Raspeig Road s/n 03690, San Vicente del Raspeig, Spain \\ blanca.calderon@ua.es; andres.fullana@ua.es
}

\section{Extended Abstract}

Nanoscale zero-valent iron (nZVI) particles have demonstrated to effectively remove a wide range of pollutants from water, such as chlorinated compounds, heavy metals and dyes. However, the use of nZVI in environmental remediation is limited do to its lack of stability and easy aggregation [1]. nZVI can also deliver the contaminants that had already been adsorbed in their surface after long period of times (aging effect) [2]. To address these issues, iron particles supported on solid porous materials are being recently developed [3]. A promising way of synthesizing this kind of materials is by encapsulation of nZVI inside micro or nano-carbon spheres via hydrothermal carbonization (HTC) from an organic compound, such as glucose or sacarose[4]. Furthermore, other compounds, as liquid wastes from agricultural and food industry could serve as carbon source for HTC synthesis of carbon-encapsulated nZVI (CE-nZVI) in order to decrease the cost of the process.

The aim of this work is to synthesize CE-nZVI from olive mill wastewater (OMWW) to treat organic and inorganic pollutants from water. The OMWW is produced during the production of olive oil, and presents a high content of organic compounds which treatment and disposal is not still solved. The OMWW, apart from producing a good quality char, contains polyolefins which present reducing properties to synthesize nZVI.

Experiments have been performed in a HTC reactor using different synthesis conditions (heating time, temperature, rate of $\mathrm{Fe} / \mathrm{C}$ ) in order to determine the optimal conditions for the synthesis of the material.

The results prove that OMWW are able to produce CE-nZVI with high surfaces area $\left(110-150 \mathrm{~m}^{2} / \mathrm{g}\right)$ and high incorporation of iron to the material (99\% compared to only $7 \%$ when using glucose as raw material) at temperatures higher than $180^{\circ} \mathrm{C}$. Furthermore, when using OMWW as starting material, CE-nZVI presents carbon spheres of lower size than when using glucose. The carbon nanocapsules produced have sizes of 100-200 nm, compared with $2 \mu \mathrm{m}$ in the case of glucose, avoid the rapid aging of nZVI and prevent the contaminants from being delivered again to the water.

This study presents a novel way of synthesizing carbon-encapsulated nZVI with improved properties than current ones, and presents an alternative for valorization of liquid biomass wastes containing high amounts of dissolved organic compounds.

\section{References}

[1] T. Phenrat, N. Saleh, K. Sirk, R. D. Tilton and G. V. Lowry, "Aggregation and sedimentation of aqueous nanoscale zerovalent iron dispersions," Environ. Sci. and Technol., vol. 41, no. 1, pp. 284-290, 2007.

[2] B. Calderon and A. Fullana, "Heavy metal release due to aging effect during zero valent iron nanoparticles remediation," Water Res., vol. 83, pp. 1-9, 2015.

[3] X. Zhu, Y. Liu, F. Qian, C. Zhou, S. Zhang and J. Chen, "Preparation of magnetic porous carbon from waste hydrochar by simultaneous activation and magnetization for tetracycline removal," Bioresour. Technol. vol. 154, pp. 209-214, 2014.

[4] B. Sunkara, J. Zhan, J. He, G. L. McPherson, G. Piringer, V. T. John, "Nanoscale zerovalent iron supported on uniform carbon microspheres for the in situ remediation of chlorinated hydrocarbons," ACS Appl. Mater. Interfaces, vol. 2, pp. 2854-2862, 2010. 